\title{
Resource Support or Emotional Trust: Effects of Perceived Organizational Support on Entrepreneurial Performance of Global Talents in China
}

\author{
Yongzhou $\mathrm{Li}^{1, \mathrm{a}}$, Shiqiu Liu ${ }^{2, \mathrm{~b}}$ \\ ${ }^{1}$ Wuhan University of Science and Technology, Hubei Institute of Science and Education Innovation and High Quality Development, \\ Wuhan, China \\ ${ }^{2}$ Wuhan University of Science and Technology, Hengda School of Management, Wuhan, China
}

\begin{abstract}
Global talents are introduced for entrepreneurship and development in China, which is not only a significant way to gather heterogeneous human capital and realize industrial transformation and upgrading in a short period of time, but also a strategic measure to drive innovative development and build an innovative country relying on talents. The regional innovation network gathers innovation elements such as upstream and downstream enterprises, universities and scientific research institutes in the industrial chain, which provides great information and resource support for global talents to gather innovation and entrepreneurship in China. Taking global talents in China as the research object, this paper constructs the relationship model among perceived organizational support, innovation network embeddedness and entrepreneurship performance in innovation network and conducts empirical research. The survey data of Global Talents in China was analyzed by SPSS 24.0 and MPLUS 7.4. The results show that the two dimensions of perceived organizational support instrumentality and emotionality have significant positive impact on entrepreneurial performance and innovation network embeddedness; while innovation network embeddedness has significant positive effects on entrepreneurial performance, but the influence of structural embeddedness is more significant than that of relational embeddedness; relational embeddedness and structural embeddedness play a partial mediating role in the influence of instrumental support and emotional support on technological innovation performance, while structural embeddedness plays a complete mediating role in the influence of instrumental support and emotional support on growth potential performance. Based on the results of empirical research, the paper proposes to further optimize the allocation of network resources, strengthen emotional support, expand the scale of innovative network, and strive to create an international talent development environment that is similar to overseas.
\end{abstract}

\section{Introduction}

The introduction and use of foreign talents as an important part of China's talent work is an effective means to accelerate the construction of a globally competitive talent system and enhance the core competitiveness of Chinese enterprises, as well as an important guarantee to drive industrial development and upgrade and realize the strategic goals of an innovative country. In recent years, as the international talent market is becoming increasingly competitive in terms of "high migration", "forward migration" and "outward migration", China has intensified its efforts to introduce overseas talents and made great efforts to build a regional innovation network platform dominated by national high-tech zones, Innovation parks and science and technology business incubators. According to statistics, by the end of 2018, a total of 5.85 million people in China had studied abroad, of whom 4.32 million had completed their studies, and 3.65 million had returned to China after completing their studies. By the second half of 2019, there are 367 Stay and Innovation parks in China, and 93,000 returnees choose to start their own businesses in stay and innovation parks. Due to the heterogeneity characteristics of overseas talents coming to China, such as high dual cultural embeddedness, high human capital investment and high value creativity, high achievement motivation and innovation and entrepreneurship consciousness, high occupational loyalty and embeddedness, as well as high knowledge information and social capital demand, a special development incentive mechanism is needed. And regional innovation network highly liberal talent flow mechanism, production, deep integration of high-tech industry cluster innovation platforms, with the option of equity incentive policy as the core of the transformation of scientific and technological achievements, in the migration and the innovation of the kernel for entrepreneurial culture and ecology, construct the global talents to a development organization support system in 
China and global talents entrepreneurship development in China and encourage development of "main channel".

Compared with local entrepreneurs, entrepreneurs with overseas background have more overseas networks and knowledge networks, and achieve innovation by introducing foreign mature ideas and technologies into China. The heterogeneous characteristics require heterogeneous organizations to support and promote their entrepreneurial development and improve entrepreneurial performance. Eisenberger ${ }^{[1]}$ first proposed that Perceived Organizational Support is perceived concern of an employee from the organization. McMillin ${ }^{[2]}$ further studied and found that Perceived Organizational Support can not only provide positive guidance in emotion, but also fully satisfy resources such as tools, equipment and information. When excellent talents perceive and receive creativity, work and social support, they are motivated to take the initiative in creative activities to improve their performance ${ }^{[3-4]}$. Considering the particularity of crosscultural background, perceived organizational support can be divided into the sense of adaptive support, the sense of professional support and the sense of economic support in the research on employees with overseas background ${ }^{[5]}$. Organizational job support have significant positive effects on returning to adapt to social relations more entrepreneurial foreign talents feel work pressure will be relatively smaller ${ }^{[6]}$, provide sufficient organizational support can help alleviate their psychological pressure, the more quickly adapt to the environment, help to enhance its confidence in the domestic environment, and improve the job satisfaction and organizational commitment ${ }^{[7]}$. Providing support in three aspects, including technical knowledge, business knowledge and international entrepreneurship orientation, is conducive to the discovery, development and utilization of entrepreneurship opportunities for outstanding talents coming to China and abroad, so that they can achieve better entrepreneurial performance $^{[8]}$.

With open innovation and cluster innovation becoming the mainstream, network embedding and its influencing mechanism on entrepreneurial performance have gradually become the focus of theoretical research in regional innovation networks. Saxenian ${ }^{[9]}$ proposed that the open communication environment, networked interpersonal relationship and loose organizational structure in Silicon Valley are more conducive to attracting innovative talents. Gulati ${ }^{[10]}$ also found that clustered innovation networks can bring information and knowledge complementing and resource sharing among heterogeneous human capital. The complexity of entrepreneurial activities determines that they must be involved in the complex network connection, which is conducive to the formation of a long-term stable relationship of trust and mutual benefit, thus contributing to the technological innovation and growth of the subject ${ }^{[11-12]}$. The sharing and complementary mechanism of innovation network is not only conducive to the development of innovation and entrepreneurship talents themselves, but also conducive to the integration of resources in the process of innovation and entrepreneurship, ultimately enhancing competitive advantages, optimizing entrepreneurial performance, and improving the success rate of innovation and entrepreneurship ${ }^{[13-14]}$. The heterogeneity of the embedding degree, status and absorption ability of overseas talents coming to China to start business in the network has significant influence on the improvement of their performance ${ }^{[15]}$. Excellent overseas talents who come to China to start businesses need to make good use of twoway resources and seize opportunities through dual network embedding to carry out entrepreneurial activities more effectively ${ }^{[16]}$. The interaction of dual networks can produce network complementary effects and promote the optimization of network resource relations ${ }^{[17]}$.

Theoretical research and management practice at home and abroad show that excellent global talents who come to Start businesses in China integrate into the network to obtain specialized resources and realize knowledge, information flow and resource sharing through homogeneous networks. Through the heterogeneous network, the complementary knowledge and skills and the flow of heterogeneous resources are realized to promote the success of innovation and entrepreneurship. Only in the innovation network can outstanding talents from abroad make up for the limitations of knowledge and information homology, homogeneity and limitation in their entrepreneurial enterprises. The location, centrality and relationship network formed by the embedded network directly determine their own sense of efficacy, thus affecting individual entrepreneurial performance. Based on this, this paper, from the perspective of social network embedding, introduces the intermediary variable of innovation network embedding, and empirically explores the incentive effect of innovative network organization resources and trust support from National High-tech Zone on the entrepreneurial development and performance improvement of excellent global talents in China. 


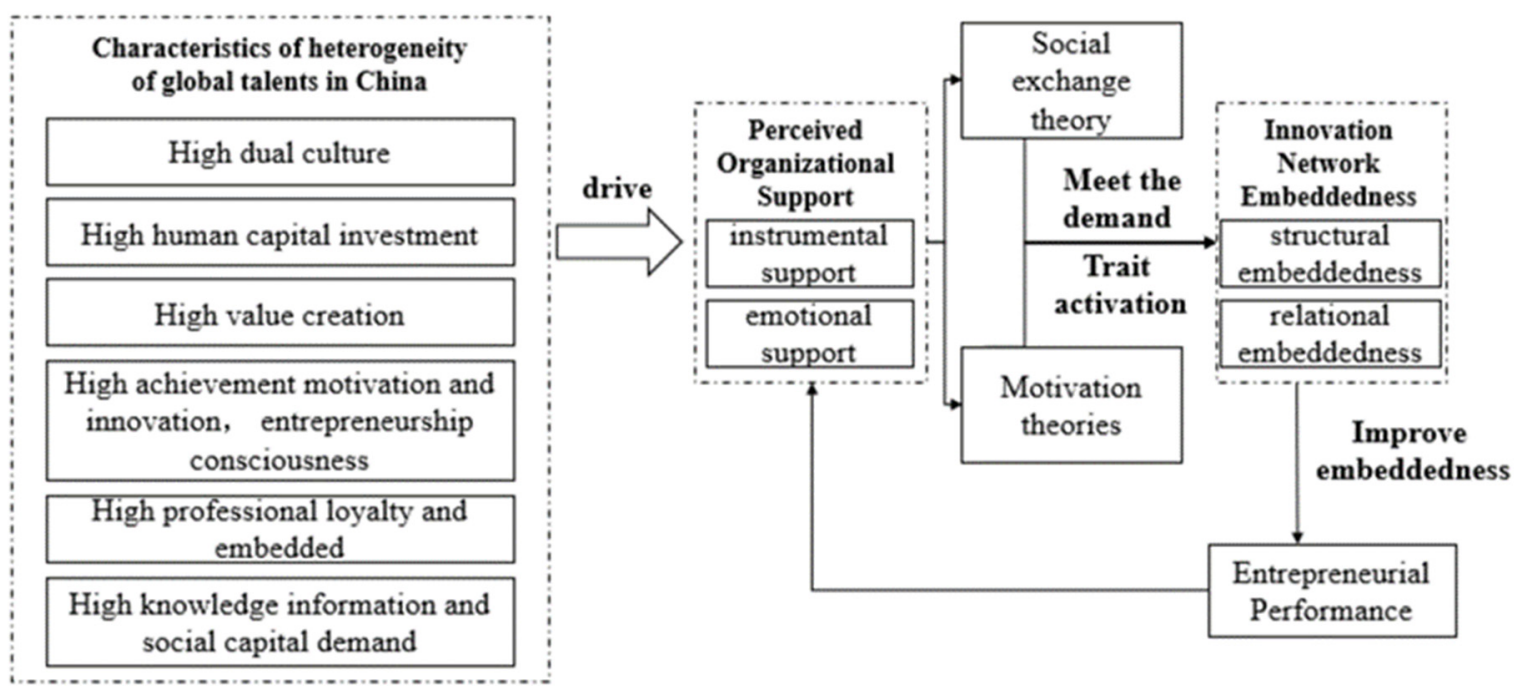

Fig1. Development Mechanism of Innovative Network Embeddedness for Global Talents in China for entrepreneurship

\section{Theoretical basis and research hypothesis}

\subsection{The relationship between perceived organizational support and entrepreneurial performance}

A number of studies on the sense of perceived organizational support have shown that it can have a positive impact on individuals and organizations, especially when the organization takes the initiative to provide support to employees, employees will cherish it more and work harder to repay the organization and achieve organizational goals ${ }^{[18]}$. Support from the organization can positively influence the identity of employees as insiders, which helps them to be more engaged in their work ${ }^{[19-20]}$. Perceived organizational support caused by higher level demands has more obvious influence on work enthusiasm ${ }^{[21]}$. Relevant studies have shown that the emotional support and instrumental support of knowledge workers have different predictive effects on work performance in different dimensions ${ }^{[22]}$, and the perceived organizational support of employees in science and technology enterprises has significant positive effects on task performance and relationship performance ${ }^{[23]}$. The theory of perceived organizational support makes up for the shortcoming of the past research on organizational behavior that only emphasizes the commitment and contribution of employees to the organization, and considers that the concern of the organization for employees is the source of the good behavior of employees.

Innovation results are not only dependent on human capital and social capital stock, but also subject to internal psychological characteristics and activity direction. The development of the value hidden in positive psychology of excellent talents is conducive to making innovation an independent behavior and improving the sustainability of performance ${ }^{[24]}$. In order to attract more foreign talents to start businesses in China, various parks such as national
High-tech Zone, Economic development Zone, Stay and Innovation Park, and science and technology business incubator have been constantly improving their internal infrastructure and issuing various preferential policies to increase their attractiveness, which creates favorable conditions for global talents to come to China to share their knowledge, skills and experience ${ }^{[25]}$. In terms of tools, excellent talents from abroad and in China can get hardware and software support provided by entrepreneurial virtual organizations to meet their own needs and actively improve their work behaviors, so as to improve their performance. All kinds of entrepreneurial information flowing within the park also enriches the information resources within the network, which is conducive to reducing the cost burden for enterprises to find information. The emotional support to foreign talents can affect the sustainability of their entrepreneurial activities. The cultural atmosphere of encouraging innovation and entrepreneurship is conducive to strengthening entrepreneurial belief and passion of entrepreneurial talents, so as to improve entrepreneurial performance. Based on this, the following hypotheses are proposed:

H1: Perceived organizational support has a significant positive predictive effect on the entrepreneurial performance of global talents in China.

H1a: Instrumental support has a significant positive predictive effect on the technological innovation performance.

H1b: Instrumental support has a significant positive predictive effect on the growth potential performance.

H1c: Emotional support has a significant positive predictive effect on the technological innovation performance.

H1d: Emotional support has a significant positive prediction effect on the growth potential performance.

\subsection{The relationship between perceived organizational support and innovation network embedding}

The establishment of networked organizational support 
for innovation and entrepreneurship can meet the requirements of resources, skills and spirit in the process of innovation and entrepreneurship of outstanding talents from abroad, and improve their adaptability and flexibility in the entrepreneurial network environment. The support of economic, cultural and institutional environment in the innovation network plays an important role in attracting talents ${ }^{[26]}$. Frequent communication and interaction among network subjects will promote the improvement of embeddedness, thus forming a stronger sense of belonging and identity ${ }^{[27]}$. The scale, density and diversity of employees' embedded organizational network are closely related to their sense of organizational support ${ }^{[28]}$. Perceived organizational support and embeddedness, as relationship mechanisms, have an impact on employees' organizational commitment and dimission ${ }^{[29]}$. From the perspective of financial support embedded in the innovation chain, Liu ${ }^{[30]}$ found that the stage of technological innovation and product innovation is mainly affected by the government's financial support, while the support effect of venture capital is the largest in the stage of achievement transformation.

At the beginning of establishment, enterprises need to rely on social network relations to obtain various resources. It is costly for them to gain trust in the process of embedding industrial network. Many start-up enterprises are faced with risks such as operation uncertainty or even enterprise bankruptcy because they cannot afford it. Within the innovation network by building organizational support, and promote the network embedded by the "express" to "tools", to improve entrepreneurial involvement, promote entrepreneurship in China foreign talents for entrepreneurial environment and entrepreneurial resources positive cognition, promote entrepreneurship network to the social relation network and industry network embedded superposition type; at the same time, under the guidance of government departments, it is conducive to the integration of various resources within the innovation network, strengthening the acquisition of innovation elements and resources, such as knowledge, information, organizational atmosphere, system and environment, trust and support for foreign talents coming to China for entrepreneurship, so as to better embed various talents and their start-ups in the innovation network. On the basis of improving resource support and emotional services, the larger the innovation network of global talents coming to China, the more central and embedded it is in the network, and the more social capital, innovation resources and heterogeneous information it can obtain, which is conducive to producing more innovation and entrepreneurship results. Based on this, the following hypotheses are proposed:

$\mathrm{H} 2$ : Perceived organizational support has a significant positive predictive effect on innovation network embedding.

H2a: Instrumental support had a significant positive predictive effect on relational embeddedness.

$\mathrm{H} 2 \mathrm{~b}$ : Instrumental support had a significant positive predictive effect on structural embeddedness.

$\mathrm{H} 2 \mathrm{c}$ : Emotional support has a significant positive predictive effect on relational embeddedness.

$\mathrm{H} 2 \mathrm{~d}$ : Emotional support has a significant positive predictive effect on structural embeddedness.

\subsection{The relationship between innovation network embedding and entrepreneurial performance}

Resources are the foundation of enterprise survival and development. Global talents coming to China for innovation and entrepreneurship expect and have the ability to make full use of the advantageous resources of enterprise organizations and networks, give full play to their own innovation momentum, explore entrepreneurial opportunities, and transform knowledge into practical value in the Chinese market, so as to achieve entrepreneurial goals. Network embedding is accompanied by economic behavior, which is not only dominated by market rules, but also restricted by social networks. In regional innovation networks, the interaction between individuals and the attributes of the whole network will influence the economic behavior of network subjects $^{[31]}$. Only in the innovation network of talents gathering can the interaction between the social capital of enterprises and the human capital of organizations be realized, the characteristics of innovation and entrepreneurship can be effectively activated, and the sense of efficiency of innovation can be stimulated, so as to influence the entrepreneurial performance of individuals. The characteristics of heterogeneous human capital determine the possibility of "embedding" in the innovation network of outstanding talents coming from abroad to start businesses in China, and diversified viewpoints and knowledge in the heterogeneous network environment have an important impact on the performance of innovation and entrepreneurship ${ }^{[32]}$. Relationship embedding mainly generates high-quality trust between the two parties, promotes the exchange and transmission of tacit knowledge, and forms a good cooperative relationship. The embedment of structure reflects the advantages of resources and information brought by network scale and network location, which is conducive to improving the entrepreneurial performance and efficiency of excellent talents from abroad in China.

Studies relations embedded effects on business performance, Mcevily et al. ${ }^{[33]}$ think mutual problem solving can help companies acquire tacit knowledge, each other trust and information sharing, in turn, affect the ability of the enterprise and the role of performance, Wu's ${ }^{[34]}$ research also shows that the relationship between the three dimensions of (trust, information sharing and joint problem solving) has a significant influence on incubation performance respectively. From the perspective of structural embedding, Arranz et al. ${ }^{[35]}$ found that structural embedding of different dimensions had different effects on project performance, and Mandakini et al. ${ }^{[36]}$ concluded that network density and centrality had positive effects on enterprise performance. From the perspective of start-up stage, when a start-up enterprise is in its initial stage, its performance is significantly affected by local network embedding. In the growth stage, the enterprise performance is mainly affected by the embedding of overseas network ${ }^{[37]}$, and the poor embedding of local environment will weaken the 
comprehensive competitive advantage of returnees in experience, technology and other aspects, and affect the improvement of entrepreneurial performance ${ }^{[38]}$. Based on this, the following hypotheses are proposed:

H3: Innovation network embedding has a significant positive prediction effect on the entrepreneurial performance of global talents in China.

H3a: Relational embeddedness has a significant positive predictive effect on the technological innovation performance.

H3b: Relational embeddedness has a significant positive prediction effect on the growth potential performance.

H3c: Structural embeddedness has a significant positive predictive effect on the technological innovation performance.

H3d: Structural embeddedness has a significant positive prediction effect on the growth potential performance.

\subsection{The mediating effect of innovation network embedding}

The National High-tech Zone and other virtual organizations have always adopted preferential policies to attract industrial agglomeration and expand the scale of entrepreneurial network, and the subjects in the agglomeration can also establish contacts at a lower cost. The higher perceived organizational support within the virtual organization is, the more favorable it is for foreign talents to be embedded in it. The park provides a series of supporting measures such as infrastructure support, financial support and technical support, and creates an innovative and entrepreneurial atmosphere, which promotes the construction of a virtual organization of entrepreneurial network, attracts more innovative and entrepreneurial enterprises, and further expands the network scale. Highly centralized network helps core knowledge sharing resources more smoothly and orderly communication, embedded in the entrepreneurs in China global talents through resource links trust and support, at a lower cost to establish a connection, the closer relationship between coupling, the more benefits to the raise of stability and trust between members of the network, formed a higher degree of behavior of tacit understanding, to reach a consensus on the higher levels of specification, reduce the uncertainty in business; By optimizing their network location, start-up enterprises with excellent global talents in China can improve the network centrality, obtain more favorable conditions and form competitive advantages, thus helping to improve the self-efficacy of excellent global talents in and optimize their entrepreneurial performance.

High network cohesion leads to long-term equality, while low network cohesion leads to more serious and persistent inequality. In the transition period, when the network is highly concentrated, high overall growth of human capital can be achieved ${ }^{[39]}$. Many studies have shown that in the virtual organization of entrepreneurial network, the influence of organizational support on the behavior and performance of enterprise subjects is generated by mediating effect. $\mathrm{Wu}^{[40]}$ believed that the stability of embedded innovation network can improve the innovation performance of small and micro science and technology enterprises, and network ability plays an intermediary role. Peng et al. ${ }^{[41]}$ also demonstrated that entrepreneurial learning plays an intermediary role in the influence of dual network embedding on the innovation performance of overseas returnees. Based on network embedding theory and knowledge management theory, other scholars found that knowledge embedding had a significant direct positive effect on knowledge creation performance, and internal and external knowledge integration played a partial mediating role between knowledge embedding and creation performance ${ }^{[42]}$. Based on this, the following hypotheses are proposed:

H4: innovation network embeddedness plays a mediating role in the influence path of perceived organizational support on entrepreneurial performance.

H4a: Relational embeddedness plays a mediating role in the path from instrumental support to technological innovation performance.

H4b: Relational embeddedness plays a mediating role in the path from emotional support to technical innovation performance.

H4c: Relational embeddedness plays a mediating role in the path from instrumental support to growth potential performance.

H4d: Relational embeddedness plays a mediating role in the path from emotional support to growth potential performance.

H4e: Structural embeddedness plays a mediating role in the path from instrumental support to technological innovation performance.

H4f: Structural embeddedness plays a mediating role in the path from emotional support to technology innovation performance.

$\mathrm{H} 4 \mathrm{~g}$ : Structural embeddedness plays a mediating role in the path from instrumental support to growth potential performance.

H4h: Structural embeddedness plays a mediating role in the path from emotional support to growth potential performance. 


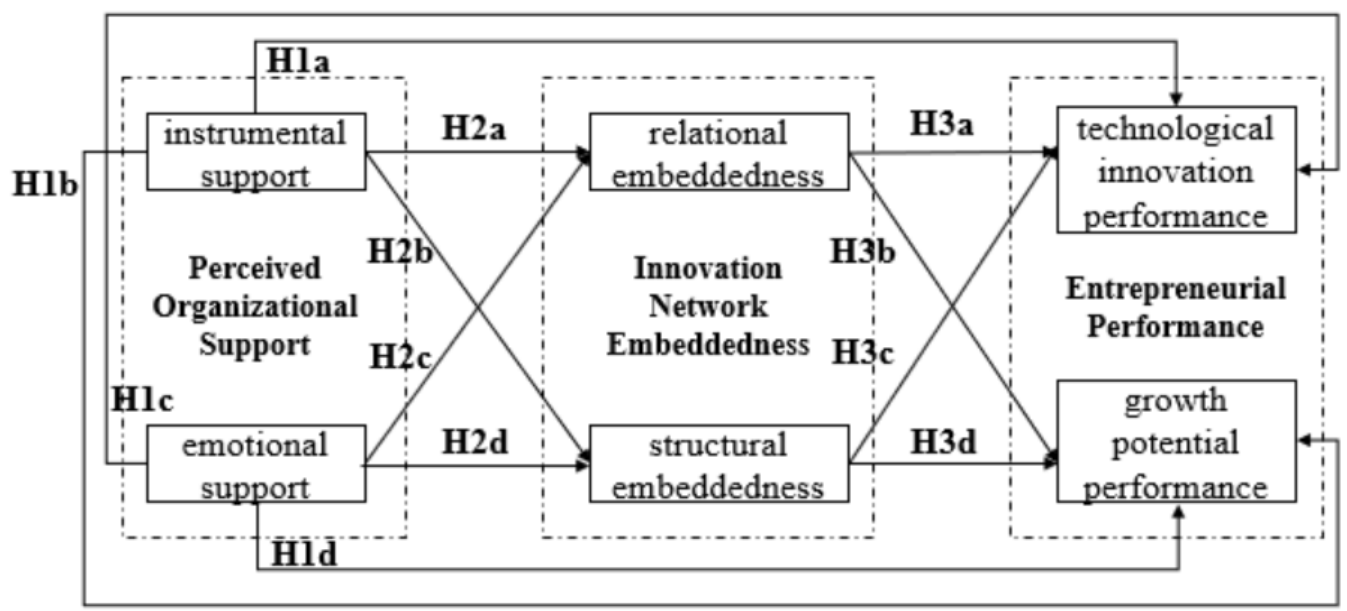

Fig2. Hypothesis Model of the Relationship among Perceived Organizational Support, Innovation Network Embeddedness and Entrepreneurial Performance

combining entrepreneurial characteristics of

\section{Research methods and survey data}

\subsection{Questionnaire measurement \\ design and variable}

The research objects of this paper are mainly excellent talents from the National High-tech Zone, economic development zone, innovation park, science and technology business incubator and other parks coming to China to start businesses and overseas. The methods of random sampling, typical investigation, field visit and indepth interview are adopted to conduct the research. To ensure the reliability and validity of this study, the measurement variables as possible will use the related domestic and foreign scholars widely used and has a good validity has maturity scale, and according to the Chinese situation and the aim of this study and the research background of related item to filter the last, in the form of combination of translation and translation to improve the accuracy of the questionnaire item. The questionnaire is designed and measured according to the basic characteristics of global talents and relevant variable characteristics with Likert 7 scale, which mainly includes the following parts:

1) The perceived organizational support scale refers to Eisenberger's ${ }^{[1]}$ research on POS scale and concept of support, and designs two dimensions including instrumental support and emotional support for the entrepreneurial environment and conditions, it also combines the service conditions within the park in my country..

2) The innovation network embeddedness scale is designed from two dimensions of relationship and structure, based on Granovetter ${ }^{[43]}$ and other research. The relationship dimension mainly refers to the research of Mcevily ${ }^{[44]}, \mathrm{Wu}^{[45]}, \mathrm{Xu}^{[46]}$, structure dimensions are mainly refer to the scale used by Granovetter, Dang ${ }^{[47]}$, $\mathrm{Jia}^{[48]}$.

3) The entrepreneurial performance scale refers to the research results of $\mathrm{Zahra}^{[49]}$ and $\mathrm{Li}^{[50]}$ and other scholars, mainly includes two dimensions: technological innovation performance and enterprise growth potential performance, entrepreneurial enterprises, especially technological startups and global entrepreneurial talents.

\subsection{Survey data}

Since 2016, this paper has carried out continuous research and expanded its coverage. It has carried out field thematic research in Wuhan, Shenzhen, Xi 'an, Kunshan and Jinan start-up communities, which are mainly national high-tech zones, and conducted informal interviews with more than 20 foreign entrepreneurs in Shanghai, Changsha and Hefei. A total of 382 samples were collected in this survey. After the validity test, the questionnaire with obvious data missing, incorrect filling and no overseas experience was eliminated, and 316 valid samples were obtained, with an effective rate of $82.7 \%$.

The basic information of effective samples is shown in Table 1. In terms of the gender of respondents, males account for $80.1 \%$, much higher than females, which is consistent with the characteristics of general entrepreneurs Due to the risks and complexity of entrepreneurial activities, excellent entrepreneurial talents from overseas generally have a long time of education, strong professional knowledge and high level of education. More entrepreneurs are 138 doctoral students and 123 master students, accounting for $82.6 \%$ of the total number. From the perspective of the nature of the park, the entrepreneurial activities of the overseas entrepreneurial talents surveyed are all in all kinds of venture parks, among which the national high-tech zone accounts for the highest proportion $(44.3 \%)$. From the perspective of overseas residence time, all the respondents have a certain number of years of overseas experience, which is in line with the expected target of the questionnaire survey. From the perspective of entrepreneurial stage, most of the enterprises where overseas excellent entrepreneurial talents are in the entrepreneurial stage and growth stage, which indicates that their entrepreneurial activities still need the help of resources from all sides. In addition, 69.9 percent of entrepreneurs own proprietary technology. 
Table1. Results for Descriptive Statistics of Sample

\begin{tabular}{|c|c|c|c|}
\hline Project & Category & $\begin{array}{c}\text { Number of } \\
\text { people }\end{array}$ & Proportion \\
\hline \multirow{2}{*}{ gender } & male & 253 & $80.1 \%$ \\
\hline & female & 63 & $19.9 \%$ \\
\hline \multirow{7}{*}{ age } & $\leqslant 25$ & 8 & $2.5 \%$ \\
\hline & $26-30$ & 58 & $18.4 \%$ \\
\hline & $31-35$ & 57 & $18.0 \%$ \\
\hline & $36-40$ & 61 & $19.3 \%$ \\
\hline & $41-45$ & 48 & $15.2 \%$ \\
\hline & $46-50$ & 29 & $9.2 \%$ \\
\hline & $\geqslant 50$ & 55 & $17.4 \%$ \\
\hline \multirow{4}{*}{ education background } & bachelor degree & 51 & $16.1 \%$ \\
\hline & Master degree & 123 & $38.9 \%$ \\
\hline & doctor's degree & 138 & $43.7 \%$ \\
\hline & otner & 4 & $1.3 \%$ \\
\hline \multirow{4}{*}{ years of entrepreneurship } & $\leqslant 1$ & 41 & $12.9 \%$ \\
\hline & $1-3$ & 98 & $31.0 \%$ \\
\hline & $3-5$ & 70 & $22.2 \%$ \\
\hline & $\geqslant 5$ & 107 & $33.9 \%$ \\
\hline \multirow[b]{2}{*}{ patent technology } & have & 221 & $69.9 \%$ \\
\hline & not have & 95 & $30.1 \%$ \\
\hline \multirow{5}{*}{ nature of park } & National High-tech Zone & 140 & $44.3 \%$ \\
\hline & $\begin{array}{l}\text { economic and technological } \\
\text { development zone }\end{array}$ & 53 & $16.8 \%$ \\
\hline & overseas students pioneer park & 90 & $28.5 \%$ \\
\hline & technology business incubator & 21 & $6.6 \%$ \\
\hline & other & 12 & $3.8 \%$ \\
\hline \multirow{4}{*}{$\begin{array}{l}\text { years of overseas } \\
\text { residence }\end{array}$} & $\leqslant 1$ & 30 & $9.5 \%$ \\
\hline & $1-3$ & 92 & $29.1 \%$ \\
\hline & $3-5$ & 62 & $19.6 \%$ \\
\hline & $\geqslant 5$ & 132 & $41.8 \%$ \\
\hline \multirow{4}{*}{ entrepreneurial stage } & initial & 146 & $46.2 \%$ \\
\hline & growth & 130 & $41.1 \%$ \\
\hline & mature & 27 & $8.6 \%$ \\
\hline & transition & 13 & $4.1 \%$ \\
\hline
\end{tabular}

\section{Model test and empirical analysis}

\subsection{Reliability and validity test}

Exploratory factor analysis was carried out on the recovered questionnaire. The KMO values of each scale were $0.911,0.908$ and 0.849 , and several items with loads less than 0.5 , cross-loads on two dimensions and unclassified factors were excluded. The Cronbach's coefficient of each latent variable was greater than 0.800 , the constituent reliability $(\mathrm{CR})$ of each variable was greater than the standard value 0.6, and the average variance extraction (AVE) was greater than the standard value 0.5 , indicating that the tool used in this study had a good convergence validity. The specific results are shown in Table 2: 
Table2. Test Results for Reliability and Validity

\begin{tabular}{|c|c|c|c|c|c|}
\hline project & category & number & proportion & project & category \\
\hline \multirow{4}{*}{ instrumental support } & 1 & 0.734 & \multirow{4}{*}{0.894} & \multirow{4}{*}{0.680} & \multirow{4}{*}{0.892} \\
\hline & 2 & 0.837 & & & \\
\hline & 3 & 0.862 & & & \\
\hline & 4 & 0.858 & & & \\
\hline \multirow{6}{*}{ emotional support } & 1 & 0.78 & \multirow{6}{*}{0.932} & \multirow{6}{*}{0.695} & \multirow{6}{*}{0.931} \\
\hline & 2 & 0.846 & & & \\
\hline & 3 & 0.808 & & & \\
\hline & 4 & 0.857 & & & \\
\hline & 5 & 0.874 & & & \\
\hline & 6 & 0.834 & & & \\
\hline \multirow{7}{*}{$\begin{array}{l}\text { relational } \\
\text { embeddedness }\end{array}$} & 1 & 0.792 & \multirow{7}{*}{0.931} & \multirow{7}{*}{0.659} & \multirow{7}{*}{0.930} \\
\hline & 2 & 0.828 & & & \\
\hline & 3 & 0.73 & & & \\
\hline & 4 & 0.852 & & & \\
\hline & 5 & 0.842 & & & \\
\hline & 6 & 0.809 & & & \\
\hline & 7 & 0.822 & & & \\
\hline \multirow{5}{*}{$\begin{array}{c}\text { structural } \\
\text { embeddedness }\end{array}$} & 1 & 0.803 & \multirow{5}{*}{0.904} & \multirow{5}{*}{0.655} & \multirow{5}{*}{0.902} \\
\hline & 2 & 0.776 & & & \\
\hline & 3 & 0.903 & & & \\
\hline & 4 & 0.754 & & & \\
\hline & 5 & 0.803 & & & \\
\hline \multirow{4}{*}{$\begin{array}{c}\text { growth } \\
\text { potential performance }\end{array}$} & 1 & 0.872 & \multirow{4}{*}{0.889} & \multirow{4}{*}{0.669} & \multirow{4}{*}{0.888} \\
\hline & 2 & 0.855 & & & \\
\hline & 3 & 0.73 & & & \\
\hline & 4 & 0.807 & & & \\
\hline \multirow{4}{*}{$\begin{array}{l}\text { technological } \\
\text { innovation } \\
\text { performance }\end{array}$} & 1 & 0.842 & \multirow{4}{*}{0.880} & \multirow{4}{*}{0.648} & \multirow{4}{*}{0.843} \\
\hline & 2 & 0.816 & & & \\
\hline & 3 & 0.816 & & & \\
\hline & 4 & 0.743 & & & \\
\hline
\end{tabular}

\subsection{Correlation analysis of variables}

Correlation analysis of variables shows that all variables have significant positive correlation, and the maximum value of correlation coefficient is 0.502 , the minimum value of square root of AVE is 0.805 , and the correlation coefficient between variables is smaller than the square root of AVE, indicating that variables have good discriminant validity. See Table 3 for specific results:

Table3. Results for Correlation Analysis among Variables

\begin{tabular}{|c|c|c|c|c|c|c|}
\hline Dimension & 1 & 2 & 3 & 4 & 5 & 6 \\
\hline 1 & 0.824 & & & & & \\
\hline 2 & $0.339 * *$ & 0.834 & & & & \\
\hline 3 & $0.325 * *$ & $0.301 * *$ & 0.812 & & & \\
\hline 4 & $0.331 * *$ & $0.323 * *$ & $0.264 * *$ & 0.809 & & \\
\hline 5 & $0.235^{* *}$ & $0.294 * *$ & $0.268 * *$ & $0.502 * *$ & 0.818 & \\
\hline 6 & $0.361 * *$ & $0.369 * *$ & $0.405 * *$ & $0.379 * *$ & $0.284 * *$ & 0.805 \\
\hline
\end{tabular}

Dimension 1-instrumental support; Dimension 2- emotional support; Dimension 3-relational embeddedness; Dimension 4- structural embeddedness; Dimension 5- growth potential performance ; Dimension 6 -technological innovation performance 


\subsection{Common method deviation test}

In this study, the unmeasurable potential method factor effect control method was used to test whether the data had common method deviation. The measurement items of perceived organizational support scale, innovation network embeddedness and entrepreneurial performance scale were loaded onto one factor to form a single-factor model. According to the scale, all items are corresponding to six dimensions to form a six-factor model. On the basis of the six-factor model, all items were loaded onto unknown covariant factors to form the seven-factor model.
As can be seen from Table 4, the fitting indexes of the single-factor model are all poor, failing to meet acceptable standards, and the model fitting fails to pass the test, that is, all items in the scale do not belong to the same variable. Compared with the 6 -factor model, the chi-square $\chi 2 / \mathrm{df}$ of the 7-factor model showed little change, and the change of RMSEA, CFI and TLI was not significant, and the SRMR index increased by 0.041 after adding covariant factor, which was higher than the fitting standard. Therefore, there is no common method variation in the scale designed in this study, and the data obtained from the survey are reasonable and reliable.

Table4. Fitness Index Value of Common Method Variation Model

\begin{tabular}{|c|c|c|c|c|c|c|c|}
\hline Indicators & $\chi^{2}$ & $d f$ & $\chi^{2 / d f}$ & RMSEA & SRMR & CFI & $T L I$ \\
\hline Single factor & 4385.649 & 405 & 10.829 & 0.176 & 0.152 & 0.385 & 0.34 \\
\hline Six factors & 556.404 & 390 & 1.427 & 0.037 & 0.038 & 0.975 & 0.972 \\
\hline Seven factors & 573.721 & 362 & 1.585 & 0.043 & 0.079 & 0.967 & 0.961 \\
\hline $\begin{array}{c}\text { Standard } \\
\text { values }\end{array}$ & --- & --- & $\leq 3$ & $\leq 0.08$ & $\leq 0.05$ & $\geq 0.9$ & $\geq 0.9$ \\
\hline
\end{tabular}

\subsection{Hypothesis testing and model validation}

To test hypotheses and verify models, the relationship models of perceived organizational support and entrepreneurial performance (model 1), perceived organizational support and innovative network embedding (model 2), innovative network embedding and entrepreneurial performance (model 3), perceived organizational support, innovative network embedding and entrepreneurial performance (Model 4) were established respectively. MPLUS7.4 was used to verify the impact of perceived organizational support on entrepreneurial performance and innovative network embedding of global talents in China, as well as the impact of innovative network embedding on entrepreneurial performance and its mediating effect. Table 5 shows the results of each fitting index of the structural equation model. All the fitting indexes are basically within the standard interval, and the overall fitting degree of the structural equation model is relatively good.

Table5. Fitness Index Value of Structural Equation Model

\begin{tabular}{|c|c|c|c|c|c|c|c|}
\hline Indicators & $\chi 2$ & $d f$ & $\chi 2 / d f$ & $\boldsymbol{R M S E A}$ & $\boldsymbol{S R M R}$ & $\boldsymbol{C F I}$ & $\boldsymbol{T L I}$ \\
\hline model 1 & 198.248 & 130 & 1.525 & 0.041 & 0.046 & 0.982 & 0.978 \\
\hline model 2 & 348.332 & 204 & 1.708 & 0.047 & 0.044 & 0.971 & 0.967 \\
\hline model 3 & 244.979 & 165 & 1.485 & 0.039 & 0.039 & 0.981 & 0.978 \\
\hline model 4 & 561.266 & 392 & 1.432 & 0.037 & 0.044 & 0.974 & 0.971 \\
\hline
\end{tabular}

Figure 3 shows the relationship path between perceived organizational support and entrepreneurial performance. It can be seen from FIG.3 that, under the condition of $\mathrm{P}<0.001$, the path coefficients of instrumental support perception on technological innovation performance and growth potential performance are 0.305 and 0.175 respectively, and the path coefficients of emotional support perception on technological innovation performance and growth potential performance are 0.299 and 0.258 respectively. This indicates that both instrumental support and emotional support have a significant positive impact on the entrepreneurial performance of foreign talents in China, and H1a, H1b, H1c and H1d have all been verified.

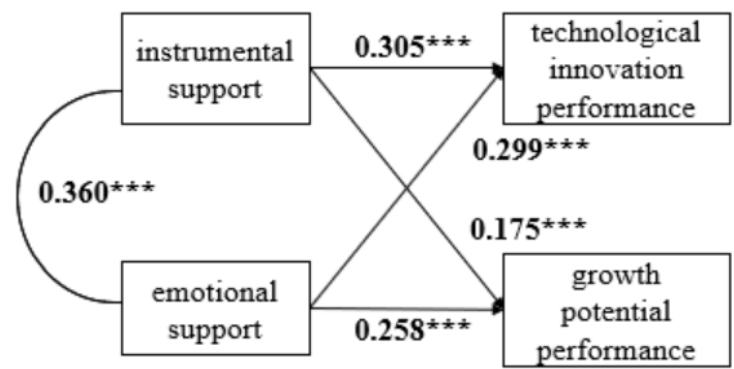

Fig3. Roadmap of Relationship between Perceived Organizational Support and Entrepreneurial Performance

Figure 4 shows the relationship path between perceived organizational support and innovation network embedding. The figure 4 shows that the $p<0.001$, under the condition of instrumental support on the embedded 
relationship and structure of embedded path coefficient was 0.270 and 0.255 , respectively, emotional support on the relationship between embedding and structural embedding of path coefficient was 0.225 and 0.272 , respectively, showed that perceived organizational support has a significant positive influence on innovation network embedded, H2a, H2b, H2c, H2d are verified.

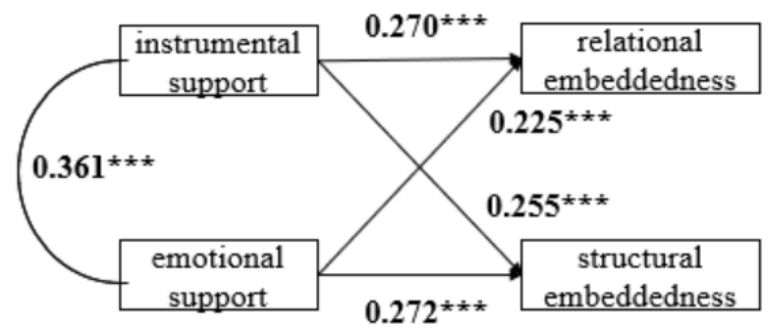

Fig4. Roadmap of Relationship between Perceived Organizational Support and Innovation Network Embeddedness

Figure 5 shows the relationship path between innovation network embedding and performance. The figure 5 shows that the $\mathrm{p}<0.001$, under the condition of embedded relation of technology innovation performance and growth potential performance of path coefficients were 0.355 and 0.144 , structure embedded on the performance of technology innovation performance and growth potential path coefficient was 0.316 and 0.521 , respectively, showing that the innovation network embedded foreign talents in China has significant positive influence on entrepreneurial performance. Therefore, $\mathrm{H} 3 \mathrm{a}$, $\mathrm{H} 3 \mathrm{~b}, \mathrm{H} 3 \mathrm{c}$ and $\mathrm{H} 3 \mathrm{~d}$ are all verified.

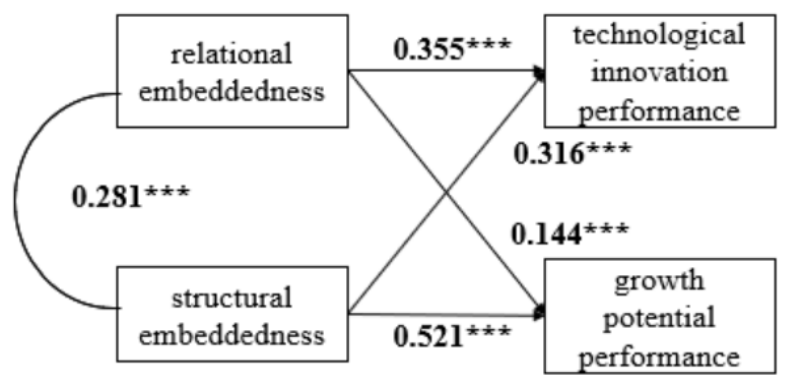

Fig5. Roadmap of Relationship between Innovation Network Embeddedness and Entrepreneurial Performance

Figure 6 shows the relationship path between perceived organizational support, innovation network embedding and entrepreneurial performance. The figure 6 shows that after the relational embeddedness and structural embeddedness, instrumental support on technology innovation performance of path coefficient reduced from 0.305 to 0.178 , emotional support on technology innovation performance of path coefficient reduced from 0.299 to 0.181 , and remained significant, support and emotional relationship between embedded in instrumental organization perceived organizational support on technology innovation performance partial intermediary role, the influence of structure embedded in instrumental sense of organization support and emotional support for the influence of the technological innovation performance partial intermediary role, $\mathrm{H} 4 \mathrm{a}, \mathrm{H} 4 \mathrm{~b}, \mathrm{H} 4 \mathrm{e}$, $\mathrm{H} 4 \mathrm{f}$ verified. And embedded control relationship and structure of embedded, instrumental sense of perceived organizational support and emotional support for the performance of growth potential path coefficients were 0.017 ( $p>0.05), 0.098(p>0.05)$, the relationship between embedded on the growth potential of path coefficient was $0.121(p>0.05)$, and therefore relations embedded in the perceived organizational support affect growth potential performance not intermediary role in the mechanism of action of H4c, H4d didn't get the validation, this structure embedded on the growth potential of the path coefficient was $0.489(p<0.001)$, Therefore, structure embedding plays a completely mediating role in the influence of perceived organizational support on growth potential performance, and $\mathrm{H} 4 \mathrm{~g}$ and $\mathrm{H} 4 \mathrm{~h}$ have been verified. Therefore, H4a, H4b, H4e, H4f, H4g and H4h are verified, while $\mathrm{H} 4 \mathrm{c}$ and $\mathrm{H} 4 \mathrm{~d}$ are not.

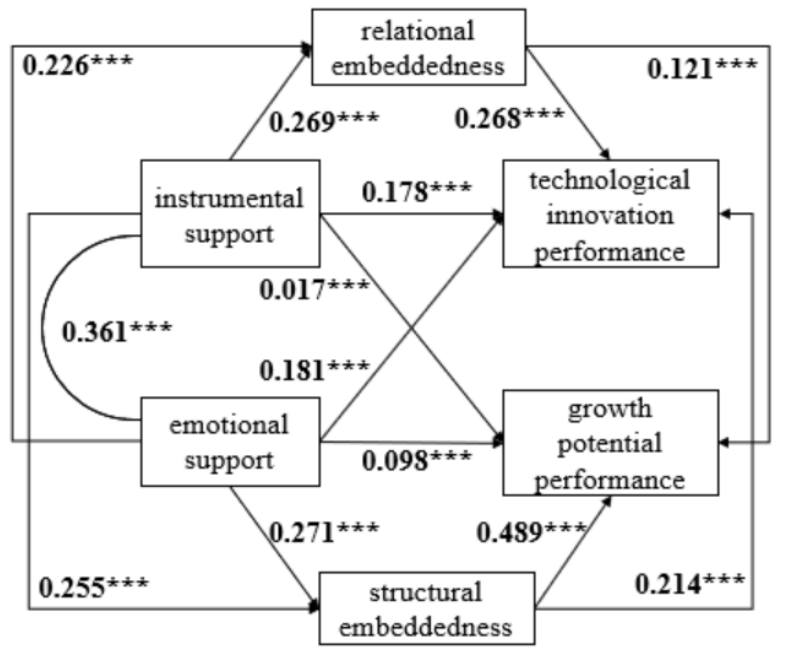

Fig6. Roadmap of Relationship among Perceived Organizational Support, Innovation Network Embeddedness and Entrepreneurial Performance

\section{Conclusion}

\subsection{Research Results}

First, perceived organizational support of global talents in China has a positive impact on network embeddedness and entrepreneurial performance. The start-up support policies provided by various parks are conducive to reducing the burden of entrepreneurship and promoting the formation of network relations within the park. At the same time, the park encourages similar enterprises to gather in space, share costs and further reduce costs, so that talents can be better embedded in the park. The park gathers a large amount of information, resources and opportunities, which can help global talents to optimize the effect and efficiency of innovation and improve the performance of entrepreneurship.

Second, in the two dimensions of innovation network embeddedness, structural embeddedness has a greater positive impact on entrepreneurial performance than relational embeddedness. From the perspective of positive influence, whether it is the realization of technological innovation or the enhancement of growth potential, network embedding to a certain extent plays an important 
role in the continuous development of entrepreneurial activities. On the one hand, relationship embeddedness can promote good cooperation, enhance trust, generate high-quality interaction. On the other hand, structural embeddedness can enjoy the resources and information advantages brought by network location. However, the effect of relationship embedding on entrepreneurial performance is relatively weak. Based on the paradox of relationship, when the relationship strength reaches a certain level, there will be more redundant information in the network, which will form a strong group consistency and reduce the promotion effect on individual entrepreneurial performance.

Thirdly, innovation network embeddedness plays a partial mediating role in the influence of perceived organizational support on technological innovation performance, while for growth potential performance, only structural embeddedness plays a complete mediating role, while relational embeddedness does not. This shows that the realization of technological innovation requires not only physical and soft support from the park, but also benign interaction and in-depth cooperation with more business entities, and it is more actively embedded in the innovation network, expanding its own network scale and obtaining advantageous central location. For growth potential performance, structure embeddedness is particularly important. It is crucial to win a more advantageous network position and give play to differentiated information advantages and control advantages. However, With the innovation network scale, to further enhance the growth potential performance requires not only innovative ideas, but more durable and adhere to focus. Excessively frequent relationship interactions may interfere with the focus of the work, occupying the main work energy, but not conducive to improvement the growth potential of the enterprise.

\subsection{Management Enlightenment}

First, the park should optimize network resource allocation and strengthen emotional support. In terms of instrumental support, the park should focus on the whole industrial chain service of global talents in China, improve the market-oriented talent introduction mechanism, and highlight the cluster effect of government-guided and market-oriented operation of human resources industrial park. The park also need to increase technical support through an international public technical service platform and improve the entrepreneurial support system. Based on the heterogeneous characteristics of global talents coming to China for entrepreneurship, the park should build a platform for information communication and exchange, lay a common discourse foundation within the network, and improve their sense of identity and support for the entrepreneurial environment.

Second, the park should expand the scale of innovation networks and lay a solid foundation for industrial development. From the perspective of structural embedding, the park shall clarify the main industrial direction, increase precision investment and improve the construction of innovative network industry. The park can make use of its platform advantages to coordinate the coordinated development between homogeneous competitive enterprises and heterogeneous complementary enterprises, forming a benign industrial linkage in terms of introducing talents, building platforms and distributing resources. The park also needs to provide high-quality industrial agglomeration network channels for global talents to start businesses in China, help their start-ups expand "circle of friends", and enable them to improve their network centrality and network resource control ability more quickly.

Third, the park should also optimize the innovation ecology and build an international talent development environment. Based on the intermediary role of relationship embedding, the park should respect the dual cultural background and living habits of outstanding talents from abroad and build an open and dynamic international talent community with an "international style". The park needs to integrate international multiculture into Chinese culture and help outstanding global talents to better integrate into China's innovation and entrepreneurship network. The park should also improve the awareness and level of service, continuously optimize the business environment, and build an international social network, so that outstanding global talents can collaborate with other innovation subjects in the network, cherish and make good use of innovation resources, carry out innovation activities more efficiently and optimize entrepreneurial performance.

\section{References}

1. Eisenberger R, Huntington R, Hutchinson S, et al. Perceived organizational support[J]. Journal of Applied Psychology, 1986, 71: 500-507.

2. McMillin R. Customer Satisfaction and Organizational Support for Service Providers[M]. USA: University of Florida, 1997.

3. Mumford M D, Scott G M, Gaddis B, et al. Leading creative people: Orchestrating expertise and relationships[J]. The Leadership Quarterly, 2002, 13(6): 705-750.

4. Akgunduz Y, Alkan C, GöK Ö A. Perceived organizational support, employee creativity and proactive personality: The mediating effect of meaning of work[J]. Journal of Hospitality and Tourism Management, 2018, 34: 105-114.

5. Kraimer M L, Wayne S J. An Examination of Perceived Organizational Support as a Multidimensional Construct in the Context of an Expatriate Assignment[J]. Journal of Management, 2004, 30(2): 209-237.

6. Yi LF, Tan Z B, Liu CcH, et al. The influence of social relations on the work pressure of knowledge workers returning from overseas -- an empirical study based on Shanghai high-tech Enterprises [J]. Journal of Research and Development Management, 2010, 22(05): 46-52.

7. Jassawalla A, Connolly T, Slojkowski L. Issues of effective repatriation: A model and Managerial 
Implications[J]. SAM Advanced Managerial Journal, 2004, 69(2): 38-46.

8. Dai O, Liu X. Returnee entrepreneurs and firm performance in Chinese high-technology industries $[\mathrm{J}]$. International Business Review, 2009, 18(4): 373-386.

9. Saxenian A L. Regional advantage: culture and competition in Silicon Valley and Route 128[M]. Cambridge, MA: Harvard University Press, 1996.

10. Gulati R, Gargiulo M. Where do inter-organizational networks come from? [J]. American Journal of Sociology, 1999, 104(5): 1439-1493.

11. Nahapiet J, Ghoshal S. Social Capital, Intellectual Capital, and the Organizational Advantage[J]. Academy of Management Reviewl, 1998, 23(2): 242266.

12. Dang J B, Tong L, Mao N. Discussion on the Relationship between resource management and innovation Performance based on crossorganizational connection in regional Innovation Network [J]. Science and Technology Progress and Countermeasures, 2013, (16): 30-34.

13. Enrico S, Yang R, Hien Thu Tran. The interplay of human and social capital in shaping entrepreneurial performance: the case of Vietnam[J]. Small Business Economics, 2013, 40(2): 435-458.

14. Park S H, Luo Y. Guanxi and organizational dynamics: organizational networking in Chinese firms[J]. Strategic Management Journal, 2001, 22(5): 455-477.

15. Gebreeyesus M, Mohnen P. Innovation performance and embeddedness in networks: evidence from the ethiopian footwear cluster[J]. World Development, 2013, 41(3): 302-316.

16. Peng W, Fu Z P. Research on entrepreneurial Behavior Process of Overseas Returnees based on Grounded Theory-- An Investigation of Entrepreneurial talents from the National "Thousand Talents Plan"[J]. Science of Science, 2015, 33(12): $1851-1860$

17. He H T, Yuan Y Z. Research on the impact of dual network embedding and interaction of overseas talent entrepreneurship on entrepreneurial performance $[\mathrm{J}]$. Journal of management, 2018, 15(01): 66-73.

18. Rhoades L, Eisenberger R. Perceived organizational support: a review of the literature[J]. Journal of Applied Psychology, 2002, 87: 698-714.

19. Lapalme M E, Stamper C L, Simard G, et al. Bringing the outside in: Can "external" workers experience insider status?[J]. Journal of Organizational Behavior, 2009, 30(7): 919-940.

20. Stamper C L, Masterson S S. Insider or Outsider? How employee perceptions of insider status affect their work behavior[J]. Journal of Organizational Behavior, 2002, 23(8): 875-894.

21. Zhang R G, Shen L, Yu L. Research on the Influence of leader-member relationship on the exuberant work of new generation employees: Multiple Mediating effects of organizational Support[J]. Modern Finance and Economics (Journal of Tianjin University of
Finance and Economics), 2019, 39(02): 103-115.

22. Chen Z X, Chen J F. Direct and Indirect effects of organizational support on Job Performance[J]. Industrial Engineering and Management, 2008(01): 99-104.

23. Fang H L, Ge Y H. Research on the Influence of Employee salary satisfaction on job Performance in science and technology Enterprises from the perspective of organizational Support[J]. Technology and Innovation Management, 2016, 37(04): 411-416.

24. Song X, Zhou Y X. Research on the effect of psychological capital on the innovation performance of knowledge Workers[J]. Journal of Shandong Agricultural University (Social Science edition), 2013, 15(01): 87-91.

25. Li M, Yang R, Wu J. Translating Transnational Capital into Professional Development: A Study of China's Thousand Youth Talents Scheme Scholars[J]. Asia Pacific Education Review, 2018, 19(2): 229-239.

26. Willoughby K W. The Affordable Resources strategy and the Milieux Embeddedness strategy as alternative approaches to facilitating innovation in a knowledgeintensive industry[J]. Journal of High Technology Management Research, 2004, 15(1): 91-121.

27. Polodny J M, Baron J N. Resources and relationships: Social networks and mobility in the workplace[J]. American Sociological Review, 1997, 62(5): 673-693.

28. Hayton J C, Carnabuci G, Eisenberger R. With a little help from my colleagues: A social embeddedness approach to perceived organizational support[J]. Journal of Organizational Behavior, 2012, 33(2): 235-249.

29. Allen D G, Shanock L R. Perceived organizational support and embeddedness as key mechanisms connecting socialization tactics to commitment and turnover among new employees[J]. Journal of Organizational Behavior, 2013, 34(3): 350-369.

30. Liu J S, Fan Z, Qi X. Research on the Heterogeneous effect of Financial Support on Embedded Innovation chain[J]. Jiangsu Social Science, 2016(5): 1-8.

31. Zhen Z H. From Network Embeddedness to Institutional Embeddedness -- The Frontier of Institutional Research in New Economic Sociology[J]. Jiangsu Social Science, 2006(3): 97-100.

32. Vasudeva G, Anand J. Unpacking Absorptive Capacity: A Study of Knowledge Utilization from Alliance Portfolios[J]. Academy of Management Journal, 2011, 54(3): 611-623.

33. Mcevily B, Marcus A. Embedded ties and the acquisition of competitive capabilities[J]. Strategic Management Journal, 2005, 26(11): 1033-1055.

34. Wu W Q, Shi K, Huang X. Network embedding, Knowledge Competence and Incubation Performance of Science and Technology Business Incubator[J]. Journal of Tianjin University (Social Science edition), 21(03): 19-31.

35. Arranz N, Arroyabe M F, Fernandez de Arroyabe J C. Network Embeddedness in Exploration and 
Exploitation of Joint R\&D Projects: A Structural Approach[J]. British Journal of Management, 2018(00): 1-17.

36. Mandakini, Nivedita. Performance evaluation of speaker recognition system, Recent trends in Security $[\mathrm{J}]$. Cloud Computing and Applications, 2019, 22(2): 203-218.

37. Yuan Yongzhi, Xiao Fangxin. Research on the Influence of Dual Network Embedding on transnational Entrepreneurship of Overseas Talents: From the Perspective of Entrepreneurship Stage[J]. Industrial Technology Economy, 2013(11): 45-53.

38. Michael S D, Olav S. Home Sweet Home: Entrepreneurs' Location Choices and the Performance of Their Ventures[J]. Management Science, 2012, 58(6): 1059-1071.

39. Cavalcanti T V V, Giannitsarou C. Growth and Human Capital: A Network Approach[J]. Economic Journal. 2017, 127(603): 1279-1317.

40. Wu S Q, Cai T T. Embedded Innovation Network and Innovation Performance of Small and Micro Science and Technology Enterprises: Research on mediating Effect of Network Capability[J]. Science and Technology Progress and Countermeasures, 2017, 34(17): 99-105.

41. Peng W, Jin D D, Fu Z P. Research on the Relationship between dual-network embedding, dualyuan entrepreneurial Learning and the Growth of Returnees' Entrepreneurial enterprises[J]. Management Review, 2018, 30(12): 63-75.

42. Liang J, Chen G H. Multiple network embedding, knowledge integration and knowledge creation Performance[J]. Journal of Scientific Research, 2019, 37(2): 301-310.

43. Granovetter M. Economic action and social structure: The problem of embeddedness[J]. American Journal of Sociology, 1985, 91(3): 481-510.

44. Mcevily B, Marcus A. Embedded ties and the acquisition of competitive capabilities[J]. Strategic Management Journal, 2005, 26(11): 1033-1055.

45. Wu X B, Xu G N, Du J. Network Embeddedness: Organizational Learning and Innovation[M]. Science Press, 2011.

46. Xu G N, Zhou Y, Liu X F. Case study on the mechanism of relationship embeddability on technological Innovation Performance[J]. Journal of Science of Science, 2011, 29(11): 1728-1735.

47. Dang $X$ H, Chang H J. Network location, geographical proximity and Enterprise Innovation Performance -- An Interactive Effect Model[J]. Scientific Research Management, 2013, 34(03): 7$13+30$.

48. Jia W F, Lou X M, Dang X H. Adaptive Simulation of knowledge flow during the formation of Core Enterprises in technology Innovation Network[J]. Systems Engineering, 2017, 35(10): 140-146.

49. Zahra S A, Ireland R D, Hitt M A. International Expansion by New Venture Firms: International
Diversity, Mode of Market Entry, Technological Learning, and Performance[J]. Academy of Management Journal, 2000, 43(5): 935-950.

50. Li H. How does new venture strategy matter in the environment performance relationship?[J]. Journal of High Technology Management Research, 2001, 12(2): 183-204. 